\title{
EFFECTS OF ANESTHESIA ON INNATE IMMUNE COMPONENTS IN ORTHOPEDIC SURGERY
}

\author{
ADNAN HAMAD AUBAID, KHALID LAHMOOD YASEEN
}

Department of Medical Microbiology, College of Medicine, University of Al-Qadisiyah, Diwaniyah, Iraq. Email: yaseenkhalid203@gmail.com Received: 06 September 2018, Revised and Accepted: 18 October 2018

\begin{abstract}
Objectives: The present study was carried out to evaluate the possible role of anesthetics and surgery on innate by measuring the levels of tumor necrosis factor alpha (TNF $\alpha$ ) and interferon gamma (IFN $\gamma$ ) by enzyme-linked immunosorbent assay (ELISA). Flow cytometry was used to determine MCP-I and CD16.
\end{abstract}

Methods: Serum level of TNF $\alpha$ and IFN $\gamma$ cytokines was measured using ELISA technique. Flow cytometry was used to determine MCP-I and CD16. White blood cell count and C-reactive protein (CRP) were determined.

Results: There was a highly significant rise in CRP blood level postoperatively when compared with pre-operative blood level ( $<<0.001$ ). In addition, the results revealed a significant rise in neutrophil count after operation in comparison with its baseline level before operation ( $\mathrm{p}<0.001$ ), while the level of lymphocytes showed significant decline following operation $(\mathrm{p}<0.001)$. The level of monocyte and eosinophil also got significantly reduced after operation $(\mathrm{p}<0.001)$, whereas the level of basophil showed no significant alteration after operation ( $\mathrm{p}=0.687)$. CD16 NK cell count revealed a significant rise during the time of anesthesia. However, it showed a significant decrease postoperatively, but the reduction did not reach baseline count. It has been noticed also that the level of MCP-1 got raised significantly in association with anesthesia induction; however, it returned back to its baseline level following surgery.

Conclusions: Analysis of data to correlate the innate immune components TNF $\alpha$, IFN $\gamma$, MCP-I, and CD16 with types of anesthetic drugs (general, local, and regional anesthesia) showed no significant association between these components and type of anesthesia ( $\mathrm{p}>0.05$ ).

Keywords: Anesthetics, Innate immunity, Interleukins, Monocyte chemoattractant protein, C-reactive protein.

(C) 2018 The Authors. Published by Innovare Academic Sciences Pvt Ltd. This is an open access article under the CC BY license (http://creativecommons. org/licenses/by/4. 0/) DOI: http://dx.doi.org/10.22159/ajpcr.2018.v11i12.29554

\section{INTRODUCTION}

Opioids, inhalational agents, intravenous, and local anesthetics have shown different effects on immune system and cytokine expression [1]. General anesthesia accompanied by surgical stress is considered to suppress immunity, presumably by directly affecting the immune system or activating the hypothalamic-pituitary-adrenal axis and the sympathetic nervous system [2]. Surgical stress and general anesthesia may suppress natural killer and cytotoxic T cells and also activate sympathetic nervous system [3]. Clusters of differentiation have numerous physiological function, which acts as receptors or ligands for signal cascade which lead to alter the cell behavior and its function in cell adhesion [4]. Chemokines play an important role in selectively recruiting monocytes, neutrophils, and lymphocytes, as well as in inducing chemotaxis through the activation of G-protein-coupled receptors [5]. MCP-1 almost made by all cells and tissues upon stimulation by different agents, but it mainly released by monocyte cells, that is why MCP-1 was first designated as monocyte chemotactic and activating factors that could lead to kill tumor targets and considered as the major chemoattractant agent in the human body [6]. The primary aim of this study was to evaluate the effects of different anesthesia techniques on some innate immunity components in orthopedic patients.

\section{METHODS}

This study was conducted on 30 patients with orthopedic surgeries and arthroscopy; 16 males (53.3\%) and 14 females (64.7\%) with the age range of 10-72 years old recruited from the Orthopedic and Rheumatology Department of AL-Diwaniayah Teaching Hospital during period from January 1,2018 , to April 30, 2018. Three types of anesthesia were used: 10 patients anesthetized with general anesthetics, 10 patients with local anesthesia, and 10 patients with local anesthesia with duration of anesthesia ranging 75 min (15-90 min). Sample was collected at three timing intervals $24 \mathrm{~h}$ before, during, and $12 \mathrm{~h}$ after surgery. The study population was assessed by questionnaire regarding age, gender, type of surgery, duration of anesthesia, and clinical history of other disease. Kits of ELISA are used in this study depending on sandwich enzyme immunoassay method. Micro ELISA plate provided in this kit has been pre-coated with an antibody specific to TNF $\alpha$ and IFN $\gamma$. OD for each well is calculated at once using a microplate reader spectrophotometer at the wavelength of $450 \mathrm{~nm}$.

\section{Flow cytometry}

Flow cytometry assay kits that have been used in this study are flow cytometry kit for CD16 and hematological white blood cell (WBC) count.

\section{Statistical analysis}

Data were translated into a computerized database structure. An expert statistical advice was sought for. All data were analyzed using Statistical Package for the Social Sciences software version 20 in association with Microsoft Excel 2016. To measure the strength of association between categorical variables, such as the effect of anesthetic techniques on cellular response, the odds ratio was used. Log transformation was carried out to make the distribution of variables related to CD16 natural killer cells and the level of MCP-1, normal.

\section{RESULTS}

According to the type of anesthesia, this study enrolled 10 patients with general anesthesia, 10 patients with regional anesthesia, and 10 patients with local anesthesia. The mean duration of anesthesia was $44.33 \pm 19.85 \mathrm{~min}$ and it ranged from 15 to $90 \mathrm{~min}$. Hypertension was seen in three patients $(10 \%)$, diabetes was seen also in three patients $(10 \%)$, ischemic heart disease was seen in a single patient (3.3\%), asthma was seen in single patient $(3.3 \%)$, and agranulocytosis was seen in single patient (3.3\%), as explained in Table 1 . 
The levels of tumor necrosis factor alpha (TNF $\alpha$ ) and interferon gamma (IFN $\gamma$ ) cytokines were analyzed, (TNF- $\alpha \mathrm{p}=0.741)$ and (IFN- $\gamma$ ), and all showed no significant change in relation to time of anesthesia whether pre-, peri-, and post-operative ( $p>0.05$ ), as seen in Fig. 1. The result listed in Tables 2 and 3, which associate between cytokines serum level (pre-, peri-, and post-operatively) with gender and age, showed no significant association between male and female as well as no significant correlation with age of patients $(p>0.05)$ for both cytokines including TNF $\alpha$ and IFN $\gamma$. Analysis of data to correlate the cytokines level (IFN $\gamma$ and TNF $\alpha$ ) with types of anesthetic drugs (general, local, and regional anesthesia) showed no significant association between these cytokine level and type of anesthesia ( $p>0.05$ ), as described in Table 4. Considering the time of duration of anesthesia, the result revealed that there is no significant association between cytokines level and duration of anesthesia as shown in Table 5. The results of this statistical analysis, which correlate the association between C-reactive protein (CRP) blood level and cytokines serum concentration, showed no significant association as described in Table 6.

Results of CD16 NK cells count revealed a significant rise during time of anesthesia (21.05); however, it showed significant decrease postoperatively (13.350), but the reduction did not reach baseline count. It has been noticed also that the level of MCP-1 got raised significantly in association with anesthesia induction (13.24); however, it returned back to its baseline level following surgery, as outlined in Table 7 . Table 8 shows that the count of CD16 NK cell before, perioperative, and post-operatively had no significant association with gender $(p>0.05)$.

\section{Table 1: General characteristics of the patients}

\begin{tabular}{|c|c|}
\hline Characteristic & Value \\
\hline Number of cases & 30 \\
\hline \multicolumn{2}{|l|}{ Age } \\
\hline Mean $\pm S D$ (years) & $35.67 \pm 17.53$ \\
\hline Range (minimum-maximum) years & $62(10-72)$ \\
\hline \multicolumn{2}{|l|}{ Gender } \\
\hline Male, no (\%) & $16(53.3)$ \\
\hline Female, no (\%) & $14(46.7)$ \\
\hline Male: female ratio & $1.14: 1$ \\
\hline \multicolumn{2}{|l|}{ Type of anesthesia } \\
\hline General, no (\%) & $10(33.3)$ \\
\hline Local, no (\%) & $10(33.3)$ \\
\hline Regional, no (\%) & $10(33.3)$ \\
\hline \multicolumn{2}{|l|}{ Duration of anesthesia } \\
\hline Mean \pm SD (minute) & $44.33 \pm 19.85$ \\
\hline Range (minimum-maximum) (minutes) & $75(15-90)$ \\
\hline \multicolumn{2}{|l|}{ Chronic illness } \\
\hline Hypertension, no (\%) & $3(10)$ \\
\hline Diabetes mellitus, $\mathrm{n}(\%)$ & $3(10)$ \\
\hline IHD, no (\%) & $1(3.3)$ \\
\hline Asthma, no (\%) & $1(3.3)$ \\
\hline Agranulocytosis, no (\%) & $1(3.3)$ \\
\hline
\end{tabular}

SD: Standard deviation, no: Number of cases, IHD: Ischemic heart disease.

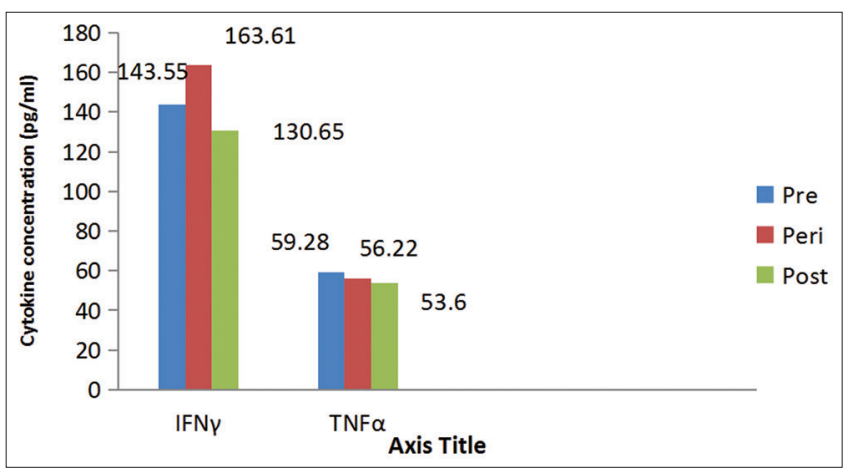

Fig. 1: Level of tumor necrosis factor alpha and interferon gamma in relation to time of anesthesi
It was also obvious that the level of the chemotactic chemokine MCP1 remains insignificantly altered before, within, and after operation ( $p>0.05)$. Neither CD16 natural killer cells nor MCP-1 showed significant correlation with age of patients ( $p>0.05)$, as demonstrated in Table 9. CD16 NK cells did not vary significantly in relation to type of anesthesia, whether local, regional, or general, in all situations whether before, at time, or after operation ( $p>0.05)$, also the level of the chemotactic chemokine MCP-1 showed no significant difference with respect to the type of anesthesia, general versus regional versus local, whatever the time in relation to anesthesia was, pre-operatively, peri-operatively and post-operatively, ( $p>0.05)$, as demonstrated in Table 10 . Regarding the correlation of immune marker with time duration of anesthesia, the results showed that immune cells, lymphocytes, showed no statistical significant correlation with duration of anesthesia ( $p>0.05$ ) [Table 11]. There was a highly significant rise in CRP blood level post-operatively when compared with pre-operative blood level, 2.65 (4.99) and 3.99 (5.64), respectively, $(\mathrm{p}<0.001)$ as shown in Fig. 3.

\section{DISCUSSION}

Variation in the type of surgical operation was proved by several authors to be associated with different types of responses to the same anesthesia techniques [7]. In the current study, there is a significant rise in neutrophil count after anesthesia in comparison with baseline level. This is in agreement with Deirmengian et al. [8]. The proposed mechanism of rising neutrophil count is most probably due to surgical trauma and associated stress with neurohumoral effect in addition

Table 2: Association of cytokine level and gender

\begin{tabular}{lllllll}
\hline \multirow{2}{*}{ Cytokine } & \multicolumn{2}{l}{ Male $(\mathbf{n = 1 6})$} & & \multicolumn{2}{l}{ Female $(\mathbf{n = 1 4 )}$} & \multirow{2}{*}{$\mathbf{p}$} \\
\cline { 2 - 3 } & Median & IQR & & Median & IQR & \\
\hline TNF $\alpha$ pre & 58.08 & 46.84 & & 61.02 & 28.41 & 0.835 \\
TNF $\alpha$ peri & 53.50 & 31.62 & & 56.55 & 13.14 & 0.560 \\
TNF $\alpha$ post & 55.02 & 14.23 & & 51.97 & 26.13 & 0.519 \\
IFN $\gamma$ pre & 140.82 & 106.51 & & 147.52 & 64.60 & 0.835 \\
IFN $\gamma$ peri & 130.40 & 71.91 & & 137.35 & 29.88 & 0.560 \\
IFN $\gamma$ post & 133.88 & 32.35 & & 126.93 & 59.39 & 0.519 \\
\hline
\end{tabular}

TNF $\alpha$ : Tumor necrosis factor alpha, IFN $\gamma$ : Interferon gamma, IQR: Interquartile range

Table 3: Correlation between age and cytokine levels

\begin{tabular}{lll}
\hline Cytokine & $\mathbf{r}$ & $\mathbf{p}$ \\
\hline Log TNF $\alpha$ pre & -0.109 & 0.565 \\
Log TNF $\alpha$ peri & 0.091 & 0.632 \\
Log TNF $\alpha$ post & -0.052 & 0.784 \\
Log IFN $\gamma$ post & -0.109 & 0.568 \\
Log IFN $\gamma$ peri & 0.087 & 0.649 \\
Log IFN $\gamma$ post & -0.047 & 0.803 \\
\hline
\end{tabular}

TNF $\alpha$ : Tumor necrosis factor alpha, IFN $\gamma$ : Interferon gamma

Table 4: Correlation between cytokine levels and type of anesthesia

\begin{tabular}{|c|c|c|c|c|c|c|c|}
\hline \multirow[t]{2}{*}{ Cytokine } & \multicolumn{2}{|c|}{$\begin{array}{l}\text { General } \\
\text { anesthesia }\end{array}$} & \multicolumn{2}{|c|}{$\begin{array}{l}\text { Local } \\
\text { anesthesia }\end{array}$} & \multicolumn{2}{|c|}{$\begin{array}{l}\text { Regional } \\
\text { anesthesia }\end{array}$} & \\
\hline & Median & IQR & Median & IQR & Median & IQR & \\
\hline TNF $\alpha$ pre & 62.11 & 35.12 & 63.64 & 41.34 & 45.86 & 14.01 & 0.115 \\
\hline TNF $\alpha$ peri & 51.53 & 19.63 & 58.51 & 42.70 & 56.22 & 12.54 & 0.558 \\
\hline TNF $\alpha$ post & 50.88 & 22.31 & 54.58 & 13.69 & 55.02 & 28.85 & 0.686 \\
\hline IFN $\gamma$ pre & 150.00 & 79.85 & 153.46 & 93.99 & 113.04 & 31.87 & 0.115 \\
\hline IFN $\gamma$ peri & 125.94 & 44.63 & 141.81 & 97.07 & 136.61 & 28.52 & 0.558 \\
\hline IFN $\gamma$ post & 124.46 & 50.71 & 132.88 & 31.12 & 133.88 & 65.59 & 0.686 \\
\hline
\end{tabular}

*Significant at $\mathrm{p} \leq 0.05$. Values were expressed as median (IQR); $n$ : Number of the cases, †Kruskal-Wallis H-test, TNF $\alpha$ : Tumor necrosis factor alpha IFN $\gamma$ : Interferon gamma, IQR: Interquartile range 
to the possibility of post-operative infection [9]. In the current study, there is a significant decline in lymphocyte count after anesthesia in comparison with baseline level. This is in agreement with Dąbrowska and Słotwiński 2014. The proposed mechanism for the reduction in lymphocyte count is the disturbance in apoptosis of lymphocyte through bcl2-dependent mechanism, by dysregulation of antiapoptosis and proapoptosis signal equilibrium [10]

In the current study, there is a significant decline in monocyte count after anesthesia in comparison with baseline level. The reason for that is most probably due to changes in immune mediators as a response to tissue injury and stress accompanying surgery, and also, there is a significant decline in eosinophil count after anesthesia in comparison with baseline level. The reason for that is most probably due to changes in immune mediators as a response to tissue injury and stress accompanying surgery. Moreover, in the current study, there is no significant change in basophil count after anesthesia in comparison with baseline level. The

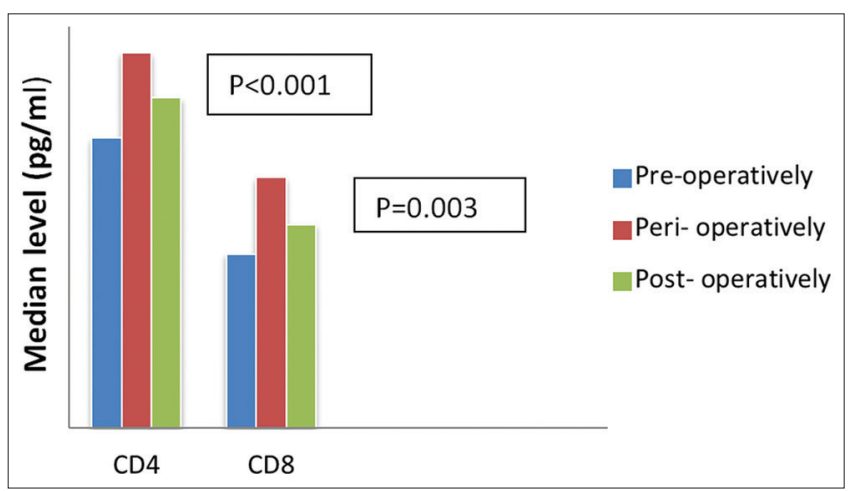

Fig. 2: Median level of immune markers in relation to operation timeline

Table 5: Correlation between cytokine levels and duration of anesthesia

\begin{tabular}{lll}
\hline Cytokine & $\mathbf{r}$ & $\mathbf{p}$ \\
\hline Log TNF $\alpha$ pre & -0.190 & 0.315 \\
Log TNF $\alpha$ peri & -0.155 & 0.412 \\
Log TNF $\alpha$ post & -0.105 & 0.580 \\
Log IFN $\gamma$ pre & -0.189 & 0.317 \\
Log IFN $\gamma$ peri & -0.159 & 0.401 \\
Log IFN $\gamma$ post & -0.112 & 0.557 \\
\hline
\end{tabular}

TNF $\alpha$ : Tumor necrosis factor alpha, IFN $\gamma$ : Interferon gamma. *Significant only at $\mathrm{p} \leq 0.05$

Table 6: Correlation between cytokine levels and CRP level

\begin{tabular}{lll}
\hline Cytokine & $\mathbf{r}$ & $\mathbf{p}$ \\
\hline Log TNF $\alpha$ pre & -0.042 & 0.826 \\
Log TNF $\alpha$ peri & 0.152 & 0.421 \\
Log TNF $\alpha$ post & 0.045 & 0.812 \\
Log IFN $\gamma$ pre & -0.033 & 0.862 \\
Log IFN $\gamma$ peri & 0.143 & 0.451 \\
Log IFN $\gamma$ Post & 0.049 & 0.799 \\
\hline
\end{tabular}

*Significant only at $\mathrm{p} \leq 0.05$. $r$ : Correlation coefficient, TNF $\alpha$ : Tumor necrosis factor alpha; IFN $\gamma$ : Interferon gamma reason for that is most probably due to changes in immune mediators as a response to tissue injury and stress accompanying surgery This is in agreement with Sayit and Terzi [8]. The present study showed that post-operative WBC count and differential counts were not significantly correlated to the age of the patient. This finding disagrees with Chen et al. [11]. The concept of aging of the immune system is recent and controversial. Several suggestions have been proposed to explain the reduced number of some cell types that are involved in adaptive and innate immune response, and the most widely accepted explanation is the aging of bone marrow and the source of all cells involved in immune system [12]. The present study showed that post-operative WBC count and differential were not significantly correlated to the gender of the patient. This is in agreement with Valiathan et al. [13]. The present

Table 8: Immune markers in relation to gender

\begin{tabular}{lllll}
\hline Marker & $\begin{array}{l}\text { Total } \mathbf{n}=\mathbf{3 0} \\
\text { mean } \pm \text { SD }\end{array}$ & $\begin{array}{l}\text { Male } \mathbf{n}=\mathbf{1 6} \\
\text { mean } \pm \text { SD }\end{array}$ & $\begin{array}{l}\text { Female } \mathbf{n}=\mathbf{1 4} \\
\text { mean } \pm \text { SD }\end{array}$ & $\mathbf{p}^{\dagger}$ \\
\hline CD16Pr & $12.45 \pm 8.14$ & $11.57 \pm 8.74$ & $12.84 \pm 8.76$ & 0.934 \\
CD16Pe & $21.05 \pm 13.36$ & $21.16 \pm 14.18$ & $20.89 \pm 15.78$ & 0.662 \\
CD16Po & $13.35 \pm 5.79$ & $11.18 \pm 7.22$ & $14.66 \pm 5.92$ & 0.934 \\
MCP-1Pr & $11.14 \pm 12.80$ & $11.25 \pm 13.27$ & $9.94 \pm 12.84$ & 1.000 \\
MCP-1Pe & $13.24 \pm 7.13$ & $13.24 \pm 11.13$ & $13.65 \pm 6.56$ & 0.771 \\
MCP-1Po & $10.79 \pm 11.64$ & $11.02 \pm 10.10$ & $10.65 \pm 11.23$ & 0.394 \\
\hline
\end{tabular}

*Significant at $\mathrm{p}<0.05$. SD: Standard deviation. Values were expressed as

median (interquartile range), n: Number of the cases, †Mann-Whitney $U$-test

Table 9: Correlation of immune markers with age

\begin{tabular}{lll}
\hline Marker & $\mathbf{R}$ & $\mathbf{p}$ \\
\hline Log CD16Pr & 0.209 & 0.268 \\
Log CD16Pe & -0.011 & 0.953 \\
Log CD16Po & 0.127 & 0.503 \\
Log MCP-1Pr & 0.020 & 0.915 \\
Log MCP-1Pe & -0.170 & 0.370 \\
Log MCP-1Po & -0.007 & 0.969 \\
\hline *Significant at $\mathrm{p}<0.05$ r: Correlation coefficient, CD: Cluster of designation
\end{tabular}

Table 10: Immune markers in relation to type of anesthesia

\begin{tabular}{llllllll}
\hline Marker & \multicolumn{2}{l}{ General } & Local & \multicolumn{3}{l}{ Regional } & P \\
\hline CD16Pr & 13.24 & 5.51 & 15.09 & 6.47 & 14.33 & 7.77 & 0.145 \\
CD16Pe & 20.09 & 17.68 & 22.98 & 15.83 & 21.16 & 11.99 & 0.557 \\
CD16Po & 12.85 & 7.06 & 13.35 & 7.70 & 13.28 & 5.88 & 0.866 \\
MCP-1Pr & 2.32 & 11.72 & 11.33 & 6.23 & 11.70 & 13.62 & 0.084 \\
MCP-1Pe & 13.98 & 15.19 & 15.00 & 5.77 & 12.46 & 6.50 & 0.673 \\
MCP-1Po & 5.01 & 10.41 & 11.44 & 8.77 & 10.97 & 9.82 & 0.093 \\
\hline
\end{tabular}

*Significant at $\mathrm{p}<0.05$ values were expressed as median (Interquartile range),

$n$ : Number of the cases, †Kruskal-Wallis H-test

Table 11: Correlation of immune markers with duration of anesthesia

\begin{tabular}{lll}
\hline Marker & $\mathbf{r}$ & $\mathbf{p}$ \\
\hline Log CD16Peri & -0.508 & 0.174 \\
Log CD16Post & 0.049 & 0.799 \\
Log MCP-1Peri & 0.069 & 0.719 \\
Log MCP-1Post & 0.095 & 0.618 \\
\hline *Significant at p<0.05 r: Correlation coefficient, CD: Cluster of designation
\end{tabular}

*Significant at $\mathrm{p}<0.05 \mathrm{r}$ : Correlation coefficient, CD: Cluster of designation

Table 7: Median level of immune markers in relation to operation timeline

\begin{tabular}{llll}
\hline Marker & Pre-operatively & Perioperatively & Post- operatively $^{\dagger}$ \\
\hline CD16, median (IQR) & $12.45(8.14)$ & $21.05(13.36)$ & $13.35(5.79)$ \\
MCP-1, median (IQR) & $11.14(12.80)$ & $13.24(7.13)$ & $10.79(11.64)$ \\
\hline Friedman & & $<0.001$ \\
\hline
\end{tabular}

${ }^{\dagger}$ Friedman test, CD: Cluster of designation, IQR: Interquartile range 


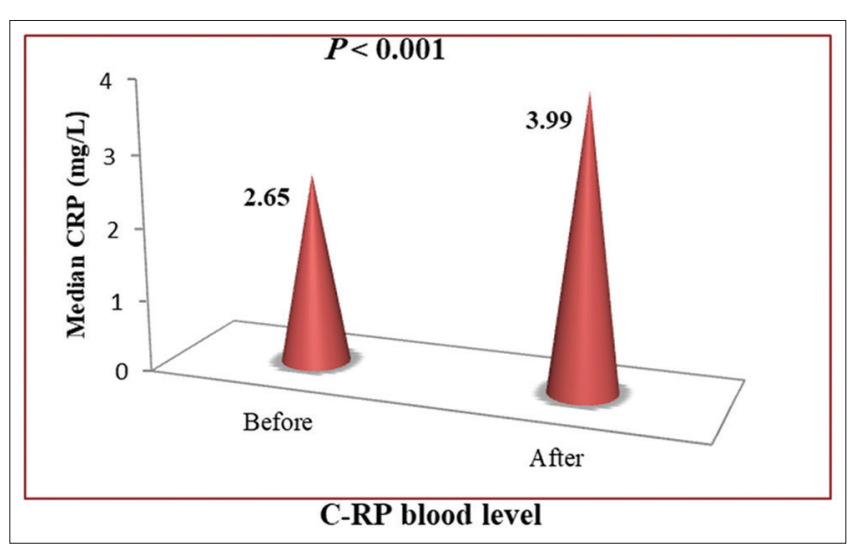

Fig. 3: C-reactive protein level before and after surgery

Table 12: WBC count before and after anesthesia

\begin{tabular}{llll}
\hline WBC & Before & After & P \\
\hline Neutrophil, mean \pm SD & $5.62 \pm 2.75$ & $6.74 \pm 2.89$ & $<0.001$ \\
lymphocyte, mean \pm SD & $3.03 \pm 1.15$ & $2.85 \pm 1.13$ & $<0.001$ \\
Monocyte, mean \pm SD & $0.65 \pm 0.25$ & $0.63 \pm 0.24$ & $<0.001$ \\
Eosinophil, mean \pm SD & $0.31 \pm 0.40$ & $0.30 \pm 0.40$ & $<0.001$ \\
Basophil, mean $\pm S D$ & $0.03 \pm 0.03$ & $0.03 \pm 0.04$ & 0.687 \\
\hline
\end{tabular}

WBC: White blood cell, SD: Standard deviation

study showed that post-operative WBC count and differential were not significantly correlated to duration of anesthesia. This finding is in agreement with Costa et al. [14]. The present study showed that postoperative WBC count and differential were not significantly correlated to the type of anesthesia. This is in agreement with Cho et al. [15]. It appears that the changes in WBC counts happened as a response to the stress accompanying surgical operation that is the mirror of humeral and neural stimulation and that trauma and tissue damage associated with surgical incision is the main stimulant factor behind these stress responses [16]. Accordingly, there will be no significant correlation with the count of WBC and the type and duration of anesthesia. In addition, the present study showed that post-operative WBC count and differential were not significantly correlated to CRP. This finding is in accordance with Boersema et al. [17]. The CRP has been shown to rise significantly in the current study, a finding that is similar to Godoy et al. [18]. The explanation for the rise of CRP is most likely to inflammation that accompanies tissue injury at the time of surgery with an increase in hepatic production of this acute phase reactant [17].

The present study showed that the level of cytokines (IFN $\gamma$ and TNF $\alpha$ ) became significantly lower during operation, whatever the type and duration of anesthesia, in comparison with their levels before operation and that their level continued to fall insignificantly after operation; however, it did not return back to the same level before operation. These results are similar to the findings of Cheng et al. [19]. The explanation for the fall in the level of these cytokines is most probably due to the antiinflammatory effect subjected by IL-10. IL-10 is an anti-inflammatory cytokine that acts by autocrine and paracrine mechanisms that cause the suppression of secretion of pro-inflammatory cytokines such as IFN $\gamma$ and TNF $\alpha$ by the same cell secreting IL-10 and other nearby cells, an effect that is named as shifting from t-helper 1 into t-helper 2 predominance [2]. The current study showed no significant correlation between any of the cytokines and gender of the patients. This finding is in agreement with Berger et al. [20]. The explanation for that is that the main difference between male and female patients is represented by certain hormonal levels, namely estrogen, progesterone, and testosterone, and these hormones have no effect on the level of inflammatory mediators [5]. The current study showed no significant correlation between any of the cytokines and age of the patients which are in agreement with Gołąbek-Dropiewska et al. [21]. The explanation for the lack of significant correlation between these cytokines and the age of the patient is most likely due to a relatively small sample size; however, substantial amount of published literature documents the negative correlation between age and immune markers due to the concept of aging of the immune system [22]. The current study showed no significant correlation between any of the cytokines and duration of anesthesia, and the duration of anesthesia has nothing to do with the level of inflammatory cytokines; therefore, the most likely explanation is that the trigger for the rise in cellular counts and immune marker is the tissue injury produced by the surgical operation and so, once tissue injury supervenes, the level of these markers get changed with disregard to the duration of anesthesia [23]. The current study showed no significant correlation between any of the cytokines and type of the anesthesia. The same previous explanation is proposed to explain the later finding; once tissue injury supervenes, the level of these markers get changed with disregard to the duration of anesthesia [24].

The present study showed that the level of immune markers CD16 and MCP-1 became significantly higher during operation, whatever the type and duration of anesthesia, in comparison with their levels before operation, and that their level decreased significantly after operation; however, it did not return back to the same level before operation (with the exception of MCP-1 which returned back almost to the same level before operation). Natural killer cell is an important player of the innate immunity, and its count is expected to rise during physiologic stress [18]. In the present study, there was no significant correlation between gender and age with MCP-1 and CD16 immune markers, and these results are in agreement with Karadeniz et al. and De Toda et al. [22,25]. In the present study, there was no significant correlation between the duration of anesthesia and immune markers (MCP-1 and CD16), and these results are in agreement with Song et al. [26]. Therefore, the most likely explanation is that the trigger for the rise in cellular counts and immune marker is the tissue injury produced by the surgical operation and so, once tissue injury supervenes, the level of these cells and markers get a rise with disregard to the duration of anesthesia [27-29]. In addition, in the present study, there was no significant correlation between type anesthesia and immune markers (MCP-1 and CD16), and these results are in agreement with Berger et al. [20].

\section{CONCLUSIONS}

Primarily, there is no significant effect for anesthesia on immune response in patients undergoing orthopedic operations. Moreover, changes in cells, immune markers, and cytokines were mainly attributable to tissue trauma during operation that is mediated by neurohumoral response.

\section{Ethical clearance}

The authors certify that they have obtained all appropriate patient consent forms. In the form, the patient(s) has/have given his/her/their consent for his/her/their images and other clinical information to be reported in the journal. The patients understand that their names and initials will not be published and due efforts will be made to conceal their identity.

\section{AUTHORS' CONTRIBUTIONS}

Adnan Hamad Aubaid: Contributing to the study design, data interpretation, and writing of manuscript. Khalid Lahmood Yaseen: Contributing to sample collection, writing the manuscript, statistical analysis, and publication.

\section{CONFLICTS OF INTEREST}

There are no conflicts of interest.

\section{REFERENCES}

1. Kitamora Y, Di Biaso I, Ingelmo PM, Bertolizio G. Anesthesia, cytokines and cancer recurrance. Glob Anesth Perioper Med 2015;1:84-92.

2. Kurosawa S, Kato M. Anesthetics, immune cells, and immune responses. J Anesth 2008;22:263-77.

3. Gu Q, Qin M, Wang B, Yu Q, Ma Y, Qin S, et al. The influence of 
anesthetic techniques on long-terms survival of colorectal cancer patients undergoing surgery: A meta-analysis. Int J Clin Exp Med 2016;9:13291-7.

4. Babatope I, Isabu PA, Imarenezor EP, Adesanya TM, Ikhimiukor AP. Normal CD4, CD8 T-lymphocytes and leucocyte baseline in healthy HIV-seronegative pregnant women in Ekpoma, Edo State, Nigeria. Int J Basic Appl Innov Res 2018;7:18-28.

5. Liu J, Dong W, Wang T, Liu L, Zhan L, Shi Y, et al. Effects of etomidate and propofol on immune function in patients with lung adenocarcinoma. Am J Transl Res 2016;8:5748-55

6. Oh YT, Qian G, Deng J, Sun SY. Monocyte chemotactic proteininduced protein-1 enhances DR5 degradation and negatively regulates DR5 activation-induced apoptosis through its deubiquitinase function. Oncogene 2018;37:3415-25

7. Eyelade O, Sanusi A, Adigun T, Adejumo O. Outcome of anesthesia in elective surgical patients with comorbidities. Ann Afr Med 2016;15:78-82.

8. Sayit E, Terzi Y. The effects of partial hip replacement surgery after hip fractures on complete blood count parameters in elderly. Int J Clin Exp Med 2017;10:7157-62.

9. Deirmengian GK, Zmistowski B, Jacovides C, O’Neil J, Parvizi J. Leukocytosis is common after total hip and knee arthroplasty. Clin Orthop Relat Res 2011;469:3031-6.

10. Dabrowska AM, Słotwiński R. The immune response to surgery and infection. Cent Eur J Immunol 2014;39:532-7.

11. Chen XF, Qian J, Pei D, Zhou C, Røe OD, Zhu F, et al. Prognostic value of perioperative leukocyte count in resectable gastric cancer. World J Gastroenterol 2016;22:2818-27.

12. Ventura MT, Casciaro M, Gangemi S, Buquicchio R. Immunosenescence in aging: Between immune cells depletion and cytokines up-regulation. Clin Mol Allergy 2017;15:21.

13. Valiathan R, Ashman M, Asthana D. Effects of ageing on the immune system: Infants to elderly. Scand J Immunol 2016;83:255-66.

14. Costa P, Nunes N, Belmonte EA, Moro JV, Lopes PC. Hematologic changes in propofol-anesthetized dogs with or without tramadol administration. Arq Bras Med Vet Zootec 2013;65:1306-12.

15. Cho HY, Jung I, Kwon JY, Kim SJ, Park YW, Kim YH, et al. The delta neutrophil index as a predictive marker of histological chorioamnionitis in patients with preterm premature rupture of membranes: A retrospective study. PLoS One 2017;12:e0173382.

16. Yuki K, Eckenhoff RG. Mechanisms of the immunological effects of volatile anesthetics: A review. Anesth Analg 2016;123:326-35.

17. Boersema $\mathrm{G}, \mathrm{Wu} \mathrm{Z}$, Menon AG, Kleinrensink GJ, Jeekel J, Lange JF, et al. Systemic inflammatory cytokines predict the infectious complications but not prolonged postoperative ileus after colorectal surgery. Mediat Inflamm 2018;2018:9.

18. Godoy D, Papa F, Campi V, del Valle M, Piñero G, Mirofsky M, et al. Relationship between baseline white blood cell and c-reactive protein with mortality in patients with spontaneous intracerebral hemorrhage. J Neurol Neurophysiol 2010;1:104

19. Cheng YC, Cheng XB, Li XJ, Wang FZ, Li ZK. Combined general and regional anesthesia and effects on immune function in patients with benign ovarian tumors treated by laparoscopic therapy. Int J Clin Exp Med 2013;6:716-9.

20. Berger M, Nadler JW, Friedman A, McDonagh DL, Bennett ER, Cooter M, et al. The effect of propofol versus isoflurane anesthesia on human cerebrospinal fluid markers of alzheimer's disease: Results of a randomized trial. J Alzheimers Dis 2016;52:1299-310.

21. Gołąbek-Dropiewska K, Pawłowska J, Witkowski J, Lasek J, Marks W, Stasiak M, et al. Analysis of selected pro-and antiinflammatory cytokines in patients with multiple injuries in the early period after trauma. Cent Eur J Immunol 2018;43:42-9.

22. Martínez de Toda I, Maté I, Vida C, Cruces J, De la Fuente M. Immune function parameters as markers of biological age and predictors of longevity. Aging (Albany NY) 2016;8:3110-9.

23. Frieri M, Kumar K, Boutin A. Trauma, sepsis, innate, adaptive immunity and inflammation. Mathews J Immunol Allergy 2017;1:4.

24. Lisowska B. The stress response and its functional implications in the immune response after surgery in patients with chronic inflammation undergoing arthroplasty. In: Recent Advances in Arthroplasty. Rijeka, Croatia: InTech; 2012.

25. Karadeniz MS, Mammadov O, Ciftci HS, Usta SA, Pembeci K. Comparing the effects of combined general/Epidural anaesthesia and general anaesthesia on serum cytokine levels in radical cystectomy. Turk J Anaesthesiol Reanim 2017;45:203-9.

26. Song P, Dong T, Zhang J, Li J, Lu W. Effects of different methods of anesthesia and analgesia on immune function and serum tumor marker levels in critically ill patients. Exp Ther Med 2017;14:2206-10.

27. Frieri M, Kumar K, Boutin A. Stress, trauma, sepsis, inflammation, management in asthma. Open J Asthma 2017;1:1-6.

28. Tri DW, Erryana M, Diah ML. Immunomodulatory effects of black cincau (Mesona palustris B1.) supplement on Escherichia coli strain o157-infected mice. Asian J Pharm Clin Res 2017;10:326-30.

29. Laxman KS, Priyadarsini S. Effect of intravenous versus intrathecal dexmedetomidine on characteristics of hyperbaric bupivacaine spinal anesthesia in lower limb surgeryasian. J Pharm Clin Res 2018;11:427-30. 